Portland State University

PDXScholar

\title{
Expressive Cartography, Boundary Objects, and the Aesthetics of Public Visualization
}

\author{
Patricio Davila \\ OCAD University \\ Dave Colangelo \\ Portland State University, dcolang2@pdx.edu \\ Robert Tu \\ OCAD University
}

Follow this and additional works at: https://pdxscholar.library.pdx.edu/ta_fac

Part of the Interactive Arts Commons, and the Interdisciplinary Arts and Media Commons Let us know how access to this document benefits you.

\section{Citation Details}

Davila, Patricio; Colangelo, Dave; and Tu, Robert, "Expressive Cartography, Boundary Objects, and the Aesthetics of Public Visualization" (2016). School of Film Faculty Publications and Presentations. 16. https://pdxscholar.library.pdx.edu/ta_fac/16

This Article is brought to you for free and open access. It has been accepted for inclusion in School of Film Faculty Publications and Presentations by an authorized administrator of PDXScholar. Please contact us if we can make this document more accessible: pdxscholar@pdx.edu. 


\section{EXPRESSIVE CARTOGRAPHY, BOUNDARY ObJects, AND the Aesthetics of Public VISUALIZATION}

Patricio Davila, Faculty of Design, OCAD University, Toronto, Canada. E-mail: pdavila@faculty.ocadu.ca

Dave Colangelo, Faculty of Liberal Arts and Sciences, OCAD University, Toronto, Canada. E-mail: dcolangelo@faculty.ocadu.ca

Maggie Chan, Faculty of Design, OCAD University, Toronto, Canada. E-mail: mach.sq@gmail.com

Robert Tu, Faculty of Design, OCAD University, Toronto, Canada.E-mail: tuchenkwan@gmail.com

See $<$ www.mitpressjournals.org/toc/leon/XX/X $>$ for supplemental files associated with this issue. $<$ Editor will fill in the $X$ ' $s>$

Submitted: <leave for Editor to date>

\section{Abstract}

Aesthetic visualization projects that incorporate users, community stakeholders, multiple modalities and technologies necessarily emphasize the way that an artistic visualization can be both an artifact and a process - a conceptualization of aesthetic visualization that is useful for thinking about visualization in general. In this paper, the authors propose the concept of the visualization as boundary object, a move away from the indexical claims of visualization and instead towards an acknowledgement of the entangled nature of social, political, economic, cultural, technological and environmental actants. Through a description of the In The Air, Tonight public visualization project, the authors suggest that by making manifest the connections between these actants, a visualization project, as a form of expressive cartography, can contribute to the visibility of and engagement with important issues (e.g. homelessness) that affect society.

In The Air, Tonight (ITAT) [1] was a public visualization project that turned the LED façade of the Ryerson Image Arts Building in Toronto into a beacon of common concern for the growing issue of homelessness in Toronto. It did so by visualizing the chilling winter wind's speed and direction with a blue wave, interrupted with a red pulse every time someone used the hashtag \#homelessness on Twitter. With this project, rather than focus on the veridical characteristics of a visualization, the focus was put on the imbrication of social and technical processes in order to demonstrate that visualizations can be seen as boundary objects, that is, an expressive assemblage that makes possible the coming together of stakeholders around a specific issue. The public visualization as boundary object is meant to be expressive instead of descriptive and represents both an object and a process of relation, discovery, and

Fig. 1. Ryerson Image Centre building with ITAT visualization. (C) Maggie Chan. Photo: Maggie Chan.)

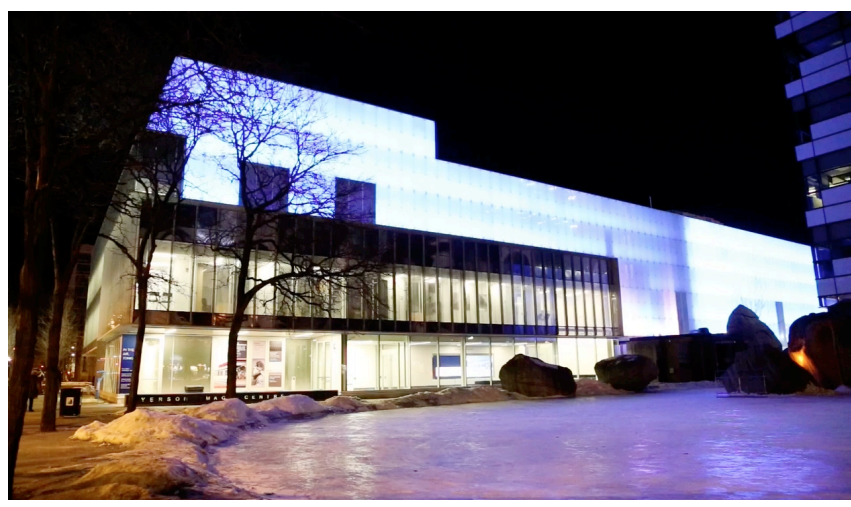

debate. This emphasis is necessary, in our opinion, to provide a new understanding of visualization projects and especially a project like ITAT.

\section{Visualization}

The visualization for ITAT was extremely simple in order to take advantage of the particular characteristics of the physical space and LED façade. More complex layers of information, given the low resolution of the façade, would simply have become confusing and difficult to correlate to a particular datum. This apparent limitation worked to our advantage as it allowed us to simultaneously relate and distinguish the two sides of the nature/culture split, namely windspeed and social communication, via the colour blue (wind) and red (\#homelessness).

In order to get the data we needed for the visualization, there were several components we used for this project. The only hardware used was a consumer-level weather station (Acurite). Software components included the Weather Underground API, Twitter API, Processing/Java applications and web development languages including JavaScript, PHP, CSS and HTML.

\section{User Experience}

The visualization of windspeed, direction and Twitter activity took place on the building as well as on the mobile devices of viewers on-site and web users off-site. This meant that visitors experienced the scale of the building's animation, the immensity of the warning signal combined with smaller, scattered experiences of red signals on smaller screens in the immediate vicinity. An embodied experience emerged of the large-scale LED light installation with reflections off the environment (e.g. windows, ice, snow, concrete) to create an overwhelming aesthetic and specular experience.

The building acted as a central beacon both physically in the city and visually in a set of interfaces offered to participants the blue and red animation tied together the visuals as displayed on the building and the mobile/desktop website. The interaction existed both onsite, where users directly responded to the physical experience of affecting the animations on the building, and also in a dispersed manner, where users could browse, tweet and retweet across the city.

\section{Rationale}

While those who experience homelessness come from all walks of life, and may be young, old, male, female, LGBTQ, sober, or addicted (and so on), what all people experiencing homelessness suffer from is overexposure to the elements. This is the underlying danger that threatens a life that has been stripped bare of its most basic supporting element: shelter. It is because of this underlying and crucial fact that we decided to stage ITAT in the middle of the winter, a time in Toronto, and in many places around the world, where shelter becomes even more important for those who find themselves without it. The interface of the LED façade, and by extension the web interface, reflects this focus on the elementary fact of the threat from the elements by visualizing a sweeping blue wave. The icy blue colour alludes to the frigid temperatures (typically in the -5 to -20 range in Toronto, plus wind chill) while the speed of the blue wave aimed to amplify the invisible yet chilling effect of the wind.

Somewhat tangentially, ITAT also refers to something else that is environmental, or 'in the air', so to speak. That is, it refers to wireless telecommunication, essentially visualizing and concretizing an otherwise amorphous, distributed process. 
While traces of this conversation are created and sensed on a disparate subset of all screens (and a relatively miniscule one at that), the sheer volume of the architectural façade and the bleeding of light into its surroundings created a data environment, making telecommunication, and this specific subset of it,

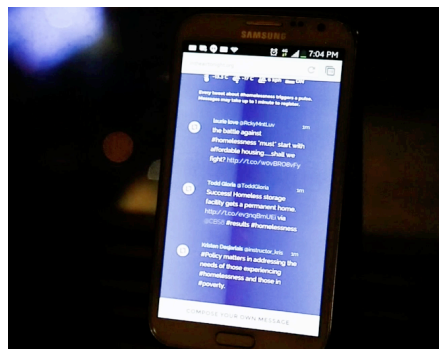

Fig. 2. ITAT mobile web interface displaying tweets and current visualization on building façade. (C) Maggie Chan. Photo: Maggie Chan.) spatially focused and apparent.

\section{Boundary Object}

A useful framework for considering the structure of ITAT is the boundary $o b$ ject. A boundary object [2] is an object (e.g. image, document, device) that makes possible the coming together of various stakeholders around a common issue. Where each stakeholder agrees to the more general components of this representation but finds specific components within the representation which suit his/her particular agenda. The strength of this concept comes from the fact that it describes specific instances in socio-technical systems which act as translators between various stakeholder groups without the need to create consensus. People can share, use, and contribute to some kind of representation of a given issue and agree to its main features but find more precise features that relate to his/her goals. In other words, a visualization can be a common ground without requiring everyone to agree to exactly what it means or represents.

For the purposes of this discussion it is useful to think of the activists, designers, users, passersby, media, viewers, etc. as party to the boundary object. Rather than rely on a polysemous or subjective reading approach to understanding how this visualization project functions, the boundary object can help model the way that a network of actants may participate in the life of a project. It is not necessary for all users, viewers, designers, activists, researchers, etc. to see the exact same thing in the visualization. In fact the power of a visualization may rest in the ability to be vague enough that people may invest in a particular representation of data to the extent that they can agree on the general contours of the issue being represented. In the case of ITAT, we can think of the association of weather and homelessness through the (aesthetic) boundary object.

\section{Discussion}

One of the explicit goals of information visualization is the reduction of complexity in the aims of augmenting human cognition and pattern recognition [3]. As a boundary object, the ITAT project may represent a reversal of this putative role of visualization where instead the complexity is posited on the interpretive and participatory side rather than on the representation of data. This project combines and visualizes three streams of data (i.e. wind speed, wind direction and Twitter activity) using a very low resolution matrix (i.e. the building LED façade) and very simple mapping of data to visual elements as discussed above. These are rather simple data sets but whose juxtaposition invites implications and interpretations which are potentially quite complex.

Furthermore, our focus on expressivity over direct and descriptive representation, and the element of mystery that invariably confronts the uninitiated viewer by way of the glowing building, served to help differentiate this data visualization as artistic or aesthetic. Artistic data visualization, according to Viegas and Wattenberg [4] does not attempt to represent the sublime (i.e. the totality of the complex problem of homelessness), but instead endeavors to point to it without undue reduction. The complexity of a problem such as homelessness renders it unrepresentable. What can be represented is complexity itself, as well as a sense of the immensity of the issue, its material reality, and the care and concern associated with it. So, while mapping wind speed and twitter activity onto the building may not be directly apparent to the passerby, nor does it solve the problem of homelessness, it expresses the complexity of the problem poetically and the stakes for the citizen: do we care enough to find out about the marginalized amongst us, those hidden in plain sight, and once privy to this complexity, are we willing to enter into it in some way?

Finally, we would suggest that artistic data visualization can be seen as a medium unto itself, a subset or stream of digital or new media art. While definitions of any form of art are by their very nature debatable, digital culture theorist Sean Cubitt [5] argues that digital art should be "communicative rather than representational" and should not be assessed for legibility but for the breadth, depth, and complexity of the networks and relations engaged and engendered in its expressions. What digital art should do, and what we have tried to do with ITAT, is not to simply seek empathy or a collective understanding of singular facts or messages, but to seek a greater understanding of the networks that create and address matters of concern by amplifying and exposing them and making them amenable to participants in a number of different ways.

\section{References and Notes}

1. In The Air, Tonight (2014), http://davecolangelo.com/project/in-the-airtonight/, accessed 1 December 2014.

2. S. Star and J. Griesemer, "Institutional Ecology, 'Translations' and Boundary Objects: Amateurs and Professionals in Berkeley's Museum of Vertebrate Zoology, 1907-39," Social Studies of Science, vol. 19, no. 3, pp. 387-420, 1989.

3. S. K. Card, J. D. Mackinlay, and B. Shneiderman, Readings in information visualization : using vision to think, vol. The Morgan Kaufmann series in interactive technologies. San Francisco, Calif.: Morgan Kaufmann Publishers, 1999.

4. F. B. Viegas and M. Wattenberg, "Artistic data visualization: Beyond visual analytics," in Proceedings of the 2nd international conference on Online communities and social computing, Beijing, China Berlin, Heidelberg, 2007.

5. S. Cubitt, "Precepts for Digital Artwork," in Fluid Screens, Expanded Cine$m a$, J. Marchessault and S. Lord, Eds. University of Toronto Press, 2007. 